
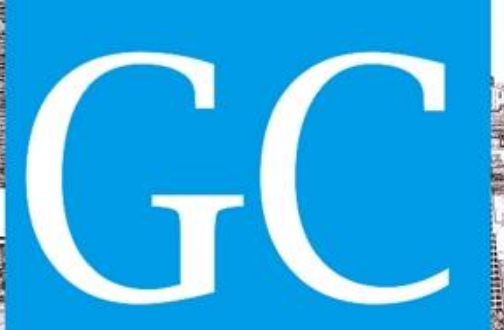

Revista Nacional de

Gerenciamento de Cidades

\title{
O desafio nacional da acessibilidade na educação para a profissionalização da Pessoa com Deficiência
}

The national challenge of education accessibility for the People with Disabilities professionalization

El reto nacional de la accesibilidad en la educación para la profesionalización de las personas con discapacidad

Patrick Verfe Schneider

Mestrando PPG-Sustentabilidade, PUC-Campinas, Brasil patrick.verfe@gmail.com

\section{Cibele Roberta Sugahara}

Professora Doutora, PUC-Campinas, Brasil Programa de Pós-Graduação em Sustentabilidade PUC Campinas cibelesu@puc-campinas.edu.br 






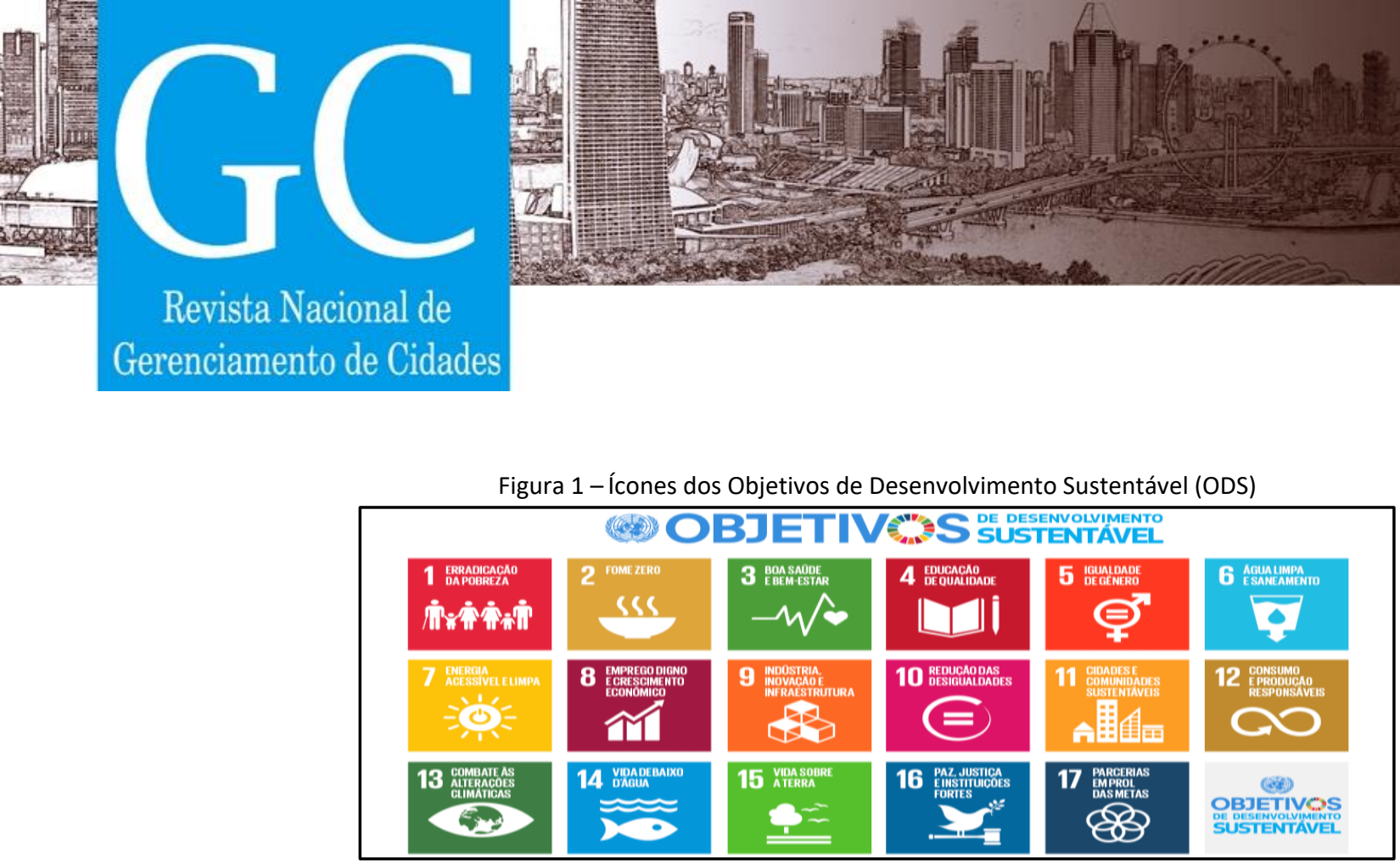

Fonte: ONU, 2018

Entende-se, como pressuposto, que nem todos os ODS trabalharão integrados para mover as ações das nações ou das empresas privadas quanto a temática da pessoa com deficiência e seu acesso ao desenvolvimento humano, através da educação formal. Deste modo, o presente estudo pautar-se-á no objetivo 4, denominado "Educação de Qualidade", que aponta diretamente para a temática da inclusão da pessoa com deficiência nos ambientes educacionais, visando a sua alavancagem profissional, por suas metas 4.5 e $4 . a$, que ambicionam, respectivamente:

Até 2030, eliminar as disparidades de gênero na educação e garantir a igualdade de acesso a todos os níveis de educação e formação profissional para os mais vulneráveis, incluindo as pessoas com deficiência, povos indígenas e as crianças em situação de vulnerabilidade" e "4.a Construir e melhorar instalações físicas para educação, apropriadas para crianças e sensíveis às deficiências e ao gênero, e que proporcionem ambientes de aprendizagem seguros e não violentos, inclusivos e eficazes para todos" (NAÇÕES UNIDAS NO BRASIL, 2015, n. p.).

Dentre todas as barreiras a serem transpostas pela pessoa com deficiência, a acessibilidade demonstra-se ainda o grande objetivo a ser superado, permitindo que o indivíduo, tenha garantidas condições similares de acesso ao universo de possibilidades que o rodeia oferecendo em plenitude a utilização de suas capacidades com vistas a aquisição de conhecimento e desenvolvimento suficientemente capazes de o libertar da necessidade de acesso ao trabalho único e exclusivamente por meio de cotas laborais (MARQUES, et al. 2018).

\section{OBJETIVO}

Analisar a educação formal no Brasil quanto a acessibilidade e inclusão da pessoa com deficiência (PCD) a partir dos meios digitais e do Censo educacional realizado em 2018 pelo Instituto Nacional de Estudos e Pesquisas Educacionais Anísio Teixeira (INEP), e apontar se 




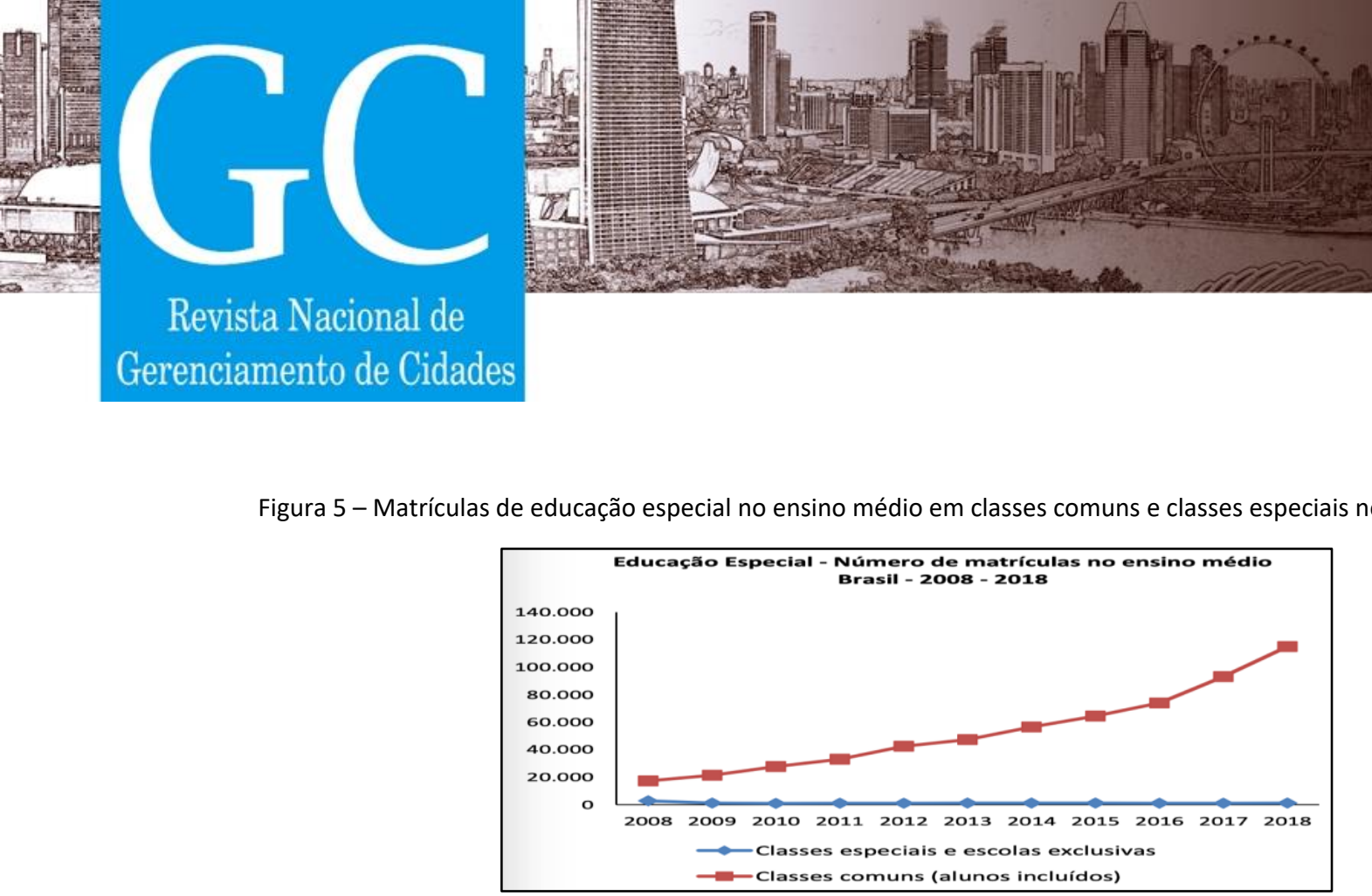

Fonte: INEP, 2018

O movimento da curva gráfica indica um crescimento de matrículas no ensino médio em classes comuns cinco vezes maior que o início da série, o que aponta para uma realidade extremamente preocupante quanto ao ambiente preparado para receber a pessoa com deficiência, sejam elementos ambientais físicos, recursos humanos colaborativos a este desenvolvimento ou ainda o material e conteúdo programático destas aulas ligadas a uma das etapas mais fundamentais do desenvolvimento intelectual da PCD, a educação de base.

Com base no exposto por estes dados capturados, percebe-se a árdua jornada da pessoa com deficiência, quanto ao acesso a educação formal a disposição nos municípios brasileiros.

As Figuras 2 a 5, juntamente com os números trazidos pelo Censo Escolar de 2018, deflagram uma situação presente no dia-a-dia da pessoa com deficiência, um baixo entendimento do valor da adaptação do espaço concreto para the receber e propiciar iguais condições de desenvolvimento de suas atividades o que acaba por prejudicar em muito a atração para a escola.

A dificuldade na atração e captação destes jovens residem, em grande parte, na acessibilidade, item igualmente prejudicial na entrada nas organizações de trabalho, embora exista o direito constitucionalmente à educação, positivado através do inciso III, do artigo 208 da CRFB/88 e da obrigação da adequação das organizações de ensino (NERI, 2004).

Um paradoxo se constrói e apresenta-se como uma fenda no país, dividindo, expectativas do mercado de trabalho de um lado e possibilidades de entrega da PCD de outro, haja vista que o acesso a educação demonstra-se um outeiro a ser transposto tão grande quanto a capacidade de adaptação da pessoa com deficiência ao ambiente laboral pouco adaptativo a sua presença. Segundo Araújo (2006, p.251) observa-se neste contexto, um problema de difícil solução e que retroalimenta esta dinâmica no universo da PCD em suas palavras

Se as empresas têm uma exigência de pelo menos oito anos de escolarização para contratação de funcionários e se as instituições que atendem PNE's não oferecem esse serviço, certamente tal nível de 



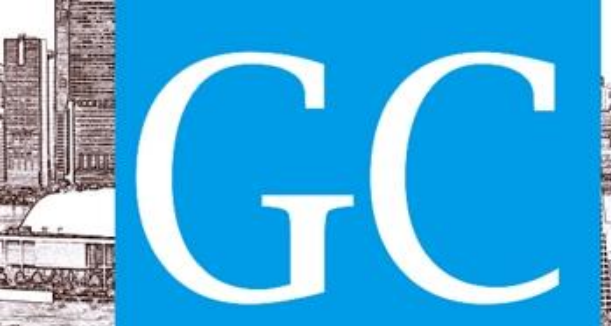

ISSN 2318-8472

\section{Revista Nacional de}

Gerenciamento de Cidades

SANTOS, Allyne Cristina dos. Inserção laboral das pessoas com deficiência nos Sistema S da cidade de São Carlos. 2018. 193f. Tese. Programa de Pós-Graduação em Educação Especial. Universidade Federal de São Carlos, São Paulo.

SILVA, C. A., MENEZES, M. A., OLIVEIRA, R.V. Às margens do desenvolvimento: o trabalho das mulheres e a luta por direitos no polo de fruticultura de Petrolina/PE-Juazeiro/BA. Cad. Pagu. n. 52, 2018. Disponível em: http://dx.doi.org/10.1590/18094449201800520008. Acesso em: 23 out. 2019.

VIDEA, Rocío de los Angeles Peredo. Comprendiendo la discapacidad intelectual: datos, critérios y reflexiones. RIP: reflexiones em psicologia, n. 15. Disponível em: http://www.scielo.org.bo/pdf/rip/n15/n15_a07. Acesso em: 22 ago. 2019. 